\title{
Evaluation of properties of the Vestibular Disorders Activities of Daily Living Scale (Brazilian version) in an elderly population
}

\author{
Natalia A. Ricci ${ }^{1}$, Mayra C. Aratani ${ }^{1}$, Heloisa H. Caovilla ${ }^{1}$, \\ Helen S. Cohen ${ }^{2}$, Fernando F. Ganança ${ }^{1}$
}

\begin{abstract}
Background: The Vestibular Disorders Activities of Daily Living Scale (VADL) is considered an important subjective assessment to evaluate patients suffering from dizziness and imbalance. Although frequently used, its metric characteristics still require further investigation. Objective: This paper aims to analyze the psychometric properties of the Brazilian version of the VADL in an elderly population. Method: The sample comprises patients ( $\geq 65$ years old) with chronic dizziness resulting from vestibular disorders. For discriminant analysis, patients were compared to healthy subjects. All subjects answered the VADL-Brazil by interview. To examine the VADL validity, patients filled out the Dizziness Handicap Inventory (DHI) and the ABC scale and were tested on the Dynamic Gait Index (DGI). To evaluate the VADL responsiveness, 20 patients were submitted to rehabilitation. Results: Patients ( $n=140)$ had a VADL total score of $4.1 \pm 1.6$ points. Healthy subjects scored significantly less than patients in all the subscales and in the VADL total score. The VADL-Brazil was weakly correlated with the DHI and moderately to the ABC scale and the DGI. Instead of the original 3 subscales, factor analysis resulted in 6 factors. The VADL was capable of detecting changes after rehabilitation, which means that the instrument has responsiveness. Conclusions: This study provided more data about the psychometric properties and usefulness of the VADL-Brazil. The use of such a reliable and valid instrument increases the knowledge about disability in patients with vestibular disorders.
\end{abstract}

Keywords: activities of daily living; vestibular diseases; rehabilitation; dizziness; geriatric assessment.

\section{HOW TO CITE THIS ARTICLE}

Ricci NA, Aratani MC, Caovilla HH, Cohen HS, Ganança FF. Evaluation of properties of the Vestibular Disorders Activities of Daily Living Scale (Brazilian version) in an elderly population. Braz J Phys Ther. 2014 Mar-Apr; 18(2):174-182. http://dx.doi. org/10.1590/S1413-35552012005000144

\section{Introduction}

Patients' self-perception of dizziness and level of independence are essential aspects to be considered in everyday practice and for the selection of therapeutic approaches in vestibular rehabilitation (VR), thus a valid and relevant assessment tool should be used ${ }^{1}$. Currently, there are many subjective assessment methods which were originally designed to evaluate patients suffering from vestibular dysfunction, such as the Dizziness Handicap Inventory (DHI) ${ }^{2}$, the Vestibular Disorders Activities of Daily Living Scale (VADL) ${ }^{3}$, the Vertigo Handicap Questionnaire $(\mathrm{VHQ})^{4}$, the Activities-specific Balance Confidence Scale (ABC scale) ${ }^{5}$, and the Vestibular Activities and Participation (VAP) $)^{6}$ measure. These questionnaires differ from each other in relation to their purposes, as well as their content ${ }^{7}$.

Amongst these questionnaires, the VADL might be considered particularly important because it aims to investigate everyday tasks which can be negatively influenced by vestibular disorders ${ }^{3}$. The VADL has been successfully used to assess limitations in activities $^{3}$, to compare features of different vestibular disorders ${ }^{8}$, and to predict diverse therapeutic approaches ${ }^{9,10}$ or VR protocol outcomes ${ }^{11-13}$. Although widely used, its metric characteristics still require further investigation ${ }^{1}$.

In order to obtain reliable results, whether in clinical practice or in research, a given questionnaire must be consistent in what it represents. Therefore, an ideal assessment tool must be valid and reproducible ${ }^{14}$. The VADL demonstrated high reliability $(r \geq 0.87)$ between two-hour test-retest analyses ${ }^{3}$. The VADLBrazilian version (VADL-Brazil) showed good sevenday test-retest and inter-rater reproducibility analyses $(r \geq 0.72 \text { and } r \geq 0.75 \text {, respectively })^{15}$. For the American and Brazilian versions ${ }^{3,15}$, the VADL total score has

\footnotetext{
${ }^{1}$ Department of Otorhinolaryngology and Head and Neck Surgery, Universidade Federal de São Paulo (UNIFESP), São Paulo, SP, Brazil ${ }^{2}$ Bobby R Alford Department of Otolaryngology - Head and Neck Surgery, Baylor College of Medicine, Houston, TX, USA Received: 06/06/2013 Revised: 08/07/2013 Accepted: 09/06/2013
} 
high internal consistency ( $\alpha=0.97$ and $\alpha=0.92$, respectively), which makes the scale unquestionably reproducible and consistent.

The validity includes many features, such as the content, criteria, and construct (structural, discriminant, and convergent). The construct validity of a scale is indicated by the agreement between its conceptual model and each of its items and dimensions, as well as its agreement with other questionnaires ${ }^{1}$. Comprehensive construct validity analyses from the VADL are still lacking ${ }^{1}$. The VADL includes three subscales (functional, locomotion, and instrumental), which were determined on a theoretical basis. Therefore, factor analysis should still be performed to improve understanding of the VADL subscales. Regarding discriminant analysis, the VADL should not only distinguish diseased from healthy people, which has already been shown ${ }^{8}$, but should also be sensitive enough to detect varied severity of vestibular disease across a spectrum range ${ }^{1}$. Convergent validity analyses, which are supposed to compare the VADL scale to similar and already published evaluation methods, demonstrated significant correlations between the latter and the $\mathrm{DHI}^{8}$. Both scales, however, are subjective; a convergent validity analysis comparing the VADL to an objective clinical evaluation method could improve its validity status. Finally, the questionnaire's responsiveness, i.e. its ability to predict significant clinical alterations ${ }^{1}$, should be considered. This attribute has not yet been widely studied for the VADL, even though studies on patients suffering from dizziness and subjected to VR have already been performed ${ }^{12,13}$.

Because of insufficient data on VADL construct validity, the present study aimed to analyze the VADL-Brazil in relation to its structural, convergent, and discriminant validity. Its responsiveness in a population of elderly patients suffering from vestibular disorders was also studied.

\section{- Method}

A cross-sectional design was used to assess construct validity features, and prospective design was used to examine responsiveness. The study was approved by the Ethics Review Board of Universidade Federal de São Paulo (UNIFESP), São Paulo, SP, Brazil, approval number 1925/09. All subjects were informed about the purposes and procedures of the study, and those who were eligible and agreed to participate signed the informed consent form.

\section{Sample and setting}

We enrolled a convenience sample of older people referred for VR to the UNIFESP Otoneurology outpatient clinic. The subjects all presented complaints of chronic dizziness resulting from vestibular disorders, which was indicated by the failure to compensate dizziness after 2 months or more from the first occurrence ${ }^{16}$. For diagnostic purposes of vestibular disorders (central, peripheral or mixed), patients were given a neurotological evaluation which included clinical history; ear, nose, and throat exam; audiological and vestibular assessments. The inclusion criteria were: 65 years old and over, both genders, and clinical diagnosis by an otolaryngologist of chronic dizziness caused by a vestibular impairment. Potential subjects were excluded if they had dizziness not resulting from vestibular disorders, cognitive deficit based on the Mini-Mental State Exam considering education level ${ }^{17}$, had had VR in the previous six months or took medication for vestibular disorders.

In order to evaluate responsiveness, 20 patients with peripheral vestibular disorders were recruited from another ongoing study on $\mathrm{VR}^{18}$. For discriminant analysis, 21 age- and sex-matched healthy subjects with no history of vestibular problem and no complaints of dizziness, vertigo or imbalance were recruited. Control subjects were mainly family members of the patients or outpatients from another clinic not related to Otoneurology.

\section{Measure}

The questionnaire analyzed in this study, known as the the VADL-Brazil ${ }^{15}$, was translated and crossculturally adapted from the original English version ${ }^{3}$. The scale comprises 28 activities divided into a 12-item Functional subscale, a 9-item Ambulation subscale, and a 7-item Instrumental subscale. Activities are classified on a 10-point qualitative scale with an additional possible rating of "not applicable" . The overall score and each subscale score are calculated by taking the medians ${ }^{8}$, with higher scores indicating more severe dependency. The Brazilian version was scored by interviewing the patients in the sample ( $n=140)$ about their current performance in daily activities compared to before the onset of the vestibular disorder. The sample with normal subjects $(n=21)$ was interviewed about their current performance in VADL activities.

For convergent validity, the VADL results of 105 patients from the whole sample were compared with the DHI total score, which ranges from zero to 100 points; and with the $\mathrm{ABC}$ scale total score, 
which ranges from zero ("no confidence") to $100 \%$ ("complete confidence") 5 . For an objective clinical measure, patients were tested on the Dynamic Gait Index (DGI) ${ }^{19}$, with a total score ranging from zero ("severe impairment") to 24 points ("normal performance") ${ }^{19}$. For discriminant validity analysis, we used the DHI "severe handicap" category, with a total score of $>60$ points $^{20}$. All tests were applied during the same visit.

To evaluate responsiveness, 20 patients were recruited to have VR with the Cawthorne ${ }^{21}$ and Cooksey ${ }^{22}$ protocol. The protocol consists of eye, head, and trunk exercises with the aim of stabilizing the eye, reducing dizziness, and improving body balance. VR was held in individual fifty-minute sessions, twice a week, for two months (total of 16 sessions). This sample was evaluated at baseline and post-treatment by means of a VADL and DHI total score reduction of 18 points or more after treatment, which is considered as "significant improvement" in quality of life $\mathrm{e}^{23}$.

\section{Statistical analysis}

The results were described with frequencies/ percentages for categorical variables and means, medians, and standard deviations for continuous variables. Data were not normally distributed; thus non-parametric tests were used. To evaluate the VADL-Brazil total score and the subscales discriminant and construct validity, Mann-Whitney $\mathrm{U}$ tests were performed among categorical variables (sex, diagnosis, controls subjects, DHI severity) and Spearman's Correlation Coefficient was calculated for continuous variables (age, number of comorbid conditions, number of medications, DHI, DGI, $\mathrm{ABC}$ scale). Correlation was considered "irrelevant" $(0>r \leq 0.25)$, "weak" $(0.25>r \leq 0.50)$, "moderate" $(0.50>r \leq 0.75)$ or "strong" $(0.75>r \leq 1.00)^{24}$. Receiver Operator Characteristic (ROC) analyses were performed, using the resulting graph to select the best cut-off points for the VADL-Brazil total score using DHI severity as the gold standard. Area under the ROC curve (AUC) values between $0.70-0.80$ have acceptable discrimination and above 0.80 , excellent discrimination ${ }^{25}$.

The VADL-Brazil structure was examined by exploratory factor analysis using Varimax rotation following the Kaiser-Meyer-Olkin (KMO) adequacy test $(>0.6)$ and Bartlett's test of sphericity $(<0.05)^{26}$. Maximum-likelihood parameter extraction was used to determine the numbers of factors to be retained for analysis $(>1)$. Item loadings were evaluated considering the cut-off $>0.40^{27}$. Finally, internal consistency was examined by Cronbach's alpha, and values between 0.60 and 0.80 were considered satisfactory ${ }^{28}$.

Responsiveness was analyzed comparing pre- and post-rehabilitation outcomes by the Wilcoxon test. The Mann-Whitney U test was used to verify the association between the VADL-Brazil total score after rehabilitation and DHI response to treatment. Data analyses were performed using SPSS17 for Windows. The significance values for all tests were set at $\mathrm{p}<0.05$.

\section{Results}

One hundred and forty elderly subjects with vestibular disorders were enrolled. Most of them were female $(76.4 \%, \mathrm{n}=107)$ with mean age of $74.1 \pm 6.7$ years, $4.8 \pm 1.8$ associated diseases, and $5.3 \pm 3.3$ medication intake. The vestibular diagnoses were peripheral $(62.1 \%, \mathrm{n}=87)$, mixed $(27.2 \%, \mathrm{n}=38)$, and central $(10.7 \%, \mathrm{n}=15)$.

The mean VADL-Brazil total score was $4.1 \pm 1.6$ points, $4.6 \pm 1.7$ points for Ambulation, $4.2 \pm 2.6$ points for Instrumental, and 3.8 \pm 1.7 points for Functional subscales. Medians were 4 for the total score and subscales. The distributions of total scores in the VADL-Brazil and the scores in each subscale are shown in Figure 1.

Most of the patients scored 4 points, including $49.2 \%$ of subjects for the total score, $56.4 \%$ for Ambulation, 39.9\% for Instrumental, and 37.9\% for the Functional subscale. The highest percentage of subjects scored above 4 in the Ambulation subscale $(35 \%, \mathrm{n}=49)$, while the Instrumental subscale had the highest number of subjects who scored 1 $(22 \%, \mathrm{n}=31)$. The Instrumental subscale was also

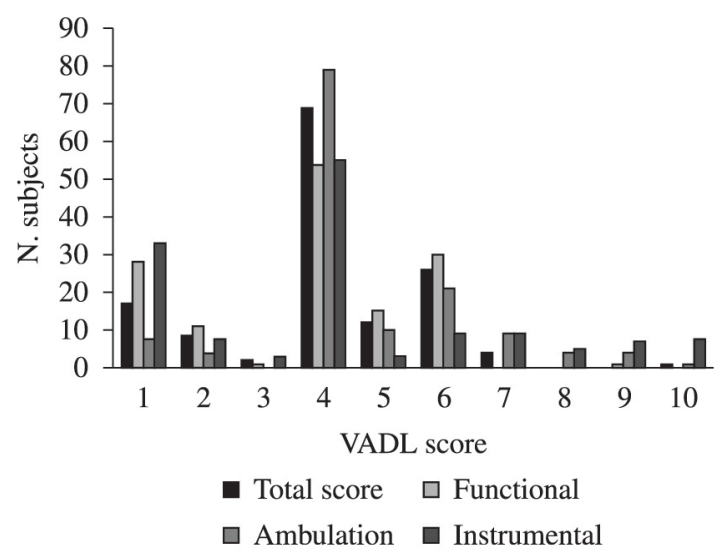

Figure 1. Total score in the Vestibular Disorders Activities of Daily Living Scale-Brazil and scores in the Functional subscale, Ambulation subscale, and Instrumental subscale. 
the subscale with most "No Response" (zero). "No Response" was scored on 2/12 items from Functional (11 and 12), 3/9 items from Ambulation (19, 20 and 21 ), and $6 / 7$ items from the Instrumental subscale (22, $23,24,25,26$, and 27). The items with the highest "No Response" were 22- Driving a car $(80.0 \%$, $\mathrm{n}=112), 12$ - Intimate activity $(72.1 \%, \mathrm{n}=101)$, and 26- Active recreation $(61.4 \%, \mathrm{n}=86)$.

\section{Construct validity}

\section{Discriminant}

Elderly subjects with vestibular disorders (peripheral $=12$, central $=2$, mixed $=12$ ) and healthy subjects (controls, $\mathrm{n}=21$ ) were compared. The samples were matched by sex (12 women and 9 men) and age ( $72.1 \pm 5.8$ years). The controls scored significantly less than patients in all the subscales $(\mathrm{p}<0.05)$ and in the VADL total score $(\mathrm{p}<0.001$; Table 1).

Comparisons between vestibular diagnosis (peripheral, central, and mixed vestibulopathy) showed no difference in the VADL total score $(\mathrm{p}=0.559)$ or in the Functional ( $\mathrm{p}=0.460)$, Ambulation $(\mathrm{p}=0.201)$, and Instrumental subscales $(\mathrm{p}=0.188)$. The VADL total score and subscales $(\mathrm{p}<0.001)$ were able to discriminate people with severe handicap based on the DHI cut-off $>60$ points (Table 1 ).

The ROC curve (Figure 2) and calculation of AUC showed that the VADL total score was able to discriminate patients with a greater severity score in the DHI and those without severity ( $\mathrm{AUC}=0.73$; 95\% CI=0.62-0.83). Based on the severity of the DHI, the cut-off point of 4 in the VADL total score can correctly classify $60 \%$ of the patients with $>60$ points in the DHI (sensitivity) and $74 \%$ of those with $\leq 60$ points (specificity).

\section{Convergent validity}

Of the total sample, 105 patients filled out the DHI and ABC scale and were tested on the DGI. No differences in characteristics (age, sex, and vestibular diagnosis) were found between samples. All of the instruments were significantly correlated with the VADL-Brazil $(\mathrm{p}<0.01)$, indicating a current validity between them. Moderate inverse correlation was found between the VADL total score and the

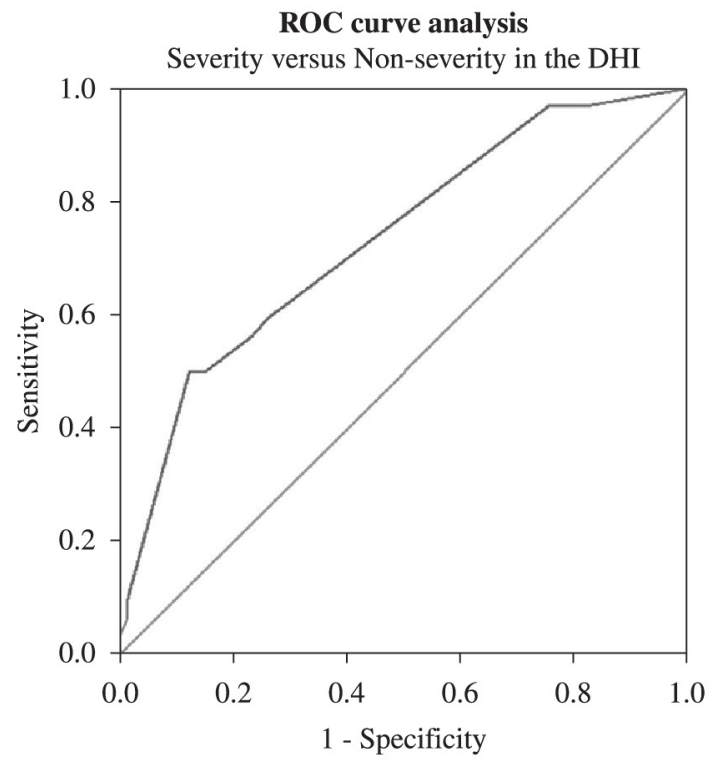

Figure 2. ROC curve analysis of VADL-Brazil total score to discriminate patient's severity in the DHI versus non-severity $(n=105)$.

Table 1. Discriminant analysis for the Vestibular Activities of Daily Living Scale total score and subscales.

\section{Mean (Standard Deviation)}

VADL Total Score Functional subscale Ambulatory subscale Instrumental subscale

Subjects

$\begin{array}{lllll}\text { Patients }(\mathrm{n}=21) & 3.59(1.71)^{* *} & 3.47(1.80)^{*} & 4.09(1.64)^{*} & 3.88(3.13)^{* *} \\ \text { Controls }(\mathrm{n}=21) & 1.71(1.30)^{* *} & 1.71(1.30)^{*} & 2.61(1.59)^{*} & 1.50(1.09)^{* *}\end{array}$

Vestibular diagnosis

Peripheral $(\mathrm{n}=87)$

4.11 (1.68)

3.74 (1.84)

4.68 (1.62)

$4.12(2.40)$

Central $(\mathrm{n}=15)$

4.43 (1.49)

4.36 (1.49)

5.13 (1.80)

$5.56(3.14)$

Mixed (n=38)

3.98 (1.63)

3.78 (1.80)

4.38 (1.87)

4.09 (2.91)

\section{DHI Severity}

$\begin{array}{lll}>60 \text { points }(\mathrm{n}=32) & 5.15(1.52)^{* *} & 5.14(1.15)^{* *} \\ \leq 60 \text { points }(\mathrm{n}=73) & 3.76(1.57)^{* *} & 3.47(1.70)^{* *}\end{array}$

Mann-Whitney $U$ test is significant at $* \mathrm{p}<0.05$ and $* * \mathrm{p}<0.001$. 
ABC scale (57.4 \pm 21.1 range; $r=-0.63)$ and the DGI (19.6 \pm 3.6 points; $r=-0.55)$. Weak correlation $(r=0.47)$ was found between the DHI $(44.2 \pm 22.3$ points) and the VADL total score.

The relationship between sex and the VADL total scores was significant $(\mathrm{p}=0.006)$, with women scoring higher than men $(4.3 \pm 1.5$ versus $3.4 \pm 1.7$ points). The significant correlation between VADL total score and age $(\mathrm{p}=0.050 ; \mathrm{r}=0.163)$ was irrelevant. The other characteristics, such as number of comorbid conditions $(\mathrm{p}=0.567, \mathrm{r}=0.049)$ and medications $(\mathrm{p}=0.820 ; \mathrm{r}=0.019)$, were not significantly correlated with the VADL total score.

\section{Structural validity}

For the factor analysis, the KMO value was 0.880 and the Bartlett test significance was $\mathrm{p}<0.0001$, which means that the correlation matrix was adequate. The analysis resulted in a 6-factor solution explaining $63.8 \%$ of the variance. The first factor explained, per se, $37.5 \%$ of the variance and had the highest Cronbach's alpha (0.88) (Table 2).

The first factor was named "Instrumental Mobility" and had 8 items derived from the original Ambulation subscale (6 items) and Instrumental subscale (2 items). The second factor was named "Basic Mobility" and consisted of 8 items, 7 of which

Table 2. Exploratory factor analysis of the Vestibular Activities of Daily Living Scale- Brazilian version ( $\mathrm{n}=140)$.

\section{VADL item}

A 19: Walking in crowds

A14: Walking uneven surfaces

A 18: Walking on open spaces

I 28: Traveling around the community

A 17: Walking in narrow spaces

A 20: Using an elevator

I 23: Carrying things while walking

I 27: Occupational role

F 10: Reaching down

F 9: Reaching overhead

F 2: Standing up from sitting on the bed or chair

F 3: Dressing the upper body

F 7: Moving in or out the bathtub or shower

A 13: Walking on level surfaces

F 1: Sitting up from lying down

F 8: Bathing yourself in the bathtub or shower

F 5: Putting on socks or stockings

F 6: Putting on shoes

F 4: Dressing the lower body

A 16: Going down steps

A 15: Going up steps

A 21: Using an escalator

I 24: Light househould chores

F 11: Meal preparation

I 25: Heavy househould chores

I 26: Active recreation

F 12: Intimate activity

I 22: Driving a car

CRONBACH'S ALPHA

Maximum likelihood
1

0.816

0.804

0.801

0.784

0.631

0.501

0.466

0.441

0.685

0.670

0.641

0.616

0.533

0.521

0.482

0.480

0.867

0.824

0.643

0.782

0.757

0.706
0.736

0.601

0.549

A: Ambulation subscale; F: Functional subscale; I: Instrumental subscale.

$\begin{array}{llllll}0.88 & 0.86 & 0.83 & 0.76 & 0.67 & 0.48 \\ 10.52 & 1.84 & 1.68 & 1.36 & 1.32 & 1.15 \\ 37.58 & 6.58 & 6.00 & 4.87 & 4.72 & 4.10\end{array}$

0.740

0.687

0.619

48

.10 
belong to the original Functional subscale and 1 from the Ambulation subscale. The third factor was named "Dressing the lower body" and consisted of 3 items that were originally from the Functional subscale. The fourth factor was named "Stairs" and all 3 items came from the Ambulation subscale. The fifth factor "Households" has 3 items, 1 from Functional Subscale and 2 from Instrumental subscale. The last factor was named "Multidimensional Activities" including 2 factors from Instrumental and 1 from Functional subscale. See Table 2.

\section{Responsiveness}

Twenty subjects with peripheral vestibular disorders were enrolled in the responsiveness analysis. Eighty percent of the patients $(n=16)$ were women, and the mean age was $73.5 \pm 6.5$ years. A significant decrease in the VADL-Brazil total score and subscales $(\mathrm{p}<0.05)$ was found after VR (Table 3 ). Also, the VADL demonstrated ability to discriminate significant improvement according to the DHI cut-off point. Patients with a reduction of 18 points or more in the DHI total score after VR had a significantly lower total score in the VADL $(2.0 \pm 1.4 ; \mathrm{n}=15)$ than those who did not achieve the cut-off point (4.0 1.8 ; $\mathrm{n}=5 ; \mathrm{p}=0.027$ ).

\section{Discussion}

The present sample painted a different scenario from that of other studies ${ }^{6,8}$ about how patients with vestibular disorders perform daily activities. For a sample with a mean age of 55 years, authors ${ }^{8}$ found a median score of 1 in the VADL total and subscales. Another study ${ }^{6}$ found a low mean score of 1.4 points in the VAP for patients with balance and/or vestibular problems and mean age of 52.6 years. These results show that most of the adult patients could perform the activities normally and believed that their functional skills were minimally or not at all affected by the vestibular disorder. Our sample with older people with chronic dizziness showed that most of these patients could perform the activities. However, after experiencing vertigo or imbalance, they adjusted their performance in an attempt to avoid triggering symptoms and especially to avoid falling.

Ageing per se was not related to increased difficulty performing VADL activities for healthy subjects. Age-related decrements do not seem to affect the performance of such well-learned tasks ${ }^{8}$. Instead, older people with vestibular disorders need to use all the reserves they have available to compensate for such problems and to learn new strategies to perform the activities. Those that require attention, strength, and sensorial resources can be more challenging for such patients.

Walking close to home was reported by older individuals with vestibular disorders as the most difficult activity to perform among 15 activities ${ }^{29}$. The environment plays an important role in how activities are performed. In the VADL, most of the activities of the Ambulation subscale are performed outside the home, such as walking in crowds. Therefore, it is not surprising that this subscale had the highest score in our study. The outdoor environment demands great eye-head coordination, body orientation, and postural stability $^{29}$. In a big city such as São Paulo, where this research was conducted, uneven sidewalks, obstacles in the street, and heavy traffic can be barriers for those patients to perform activities well and safely. Also those environmental barriers prevent elderly people with vertigo and imbalance from coming out of their homes. It is important for a therapist to determine if the environment is causing disability, train patients in such places and tasks, and whenever possible provide some adaptations to the environment.

The study shows that some activities were not performed by elderly people, i.e. driving a car, intimate activity. This is a special characteristic

Table 3. Responsiveness analysis of the Vestibular Disorders Activities of Daily Living Scale total score and subscales $(n=20)$.

\begin{tabular}{ccccc}
\hline & Evaluation & Mean (SD) & CI & Wilcoxon p \\
VADL Total Score & Baseline & $4.07(1.98)$ & $3.14-5.00$ & 0.005 \\
& Post-treatment & $2.50(1.76)$ & $1.67-3.32$ & 0.011 \\
Functional subscale & Baseline & $3.85(2.08)$ & $2.87-4.82$ & 0.007 \\
& Post-treatment & $2.55(1.73)$ & $1.74-3.36$ & $3.68-5.26$ \\
Ambulatory subscale & Baseline & $4.47(1.69)$ & $2.51-3.93$ & 0.058 \\
& Post-treatment & $3.22(1.52)$ & $2.60-4.89$ & $1.44-3.50$ \\
\hline
\end{tabular}


of this sample, which was composed mostly of widowed women and people with low income. Using the VAP, authors ${ }^{6}$ found that 9 activities showed many no responses, most of them related to physical activities and occupational roles. They stated that this result was related to the characteristics of the subjects, and therefore, a larger number of younger patients with vestibular disorders would provide greater information about such activities. Thus, the characteristics of the sample can affect the results of some activities, but retaining those questions in the scale is important to better understand the level of activities that the patient usually performs.

The VADL original version was moderately correlated with the DHI (Spearman's $r=0.66$, $\mathrm{p}<0.001)^{8}$. This result differs from the present study, in which a weak correlation was found. In our study a 4-point cut-off of the VADL total score could identify those with high severity symptoms by the DHI. A plateau in the DHI score was achieved while the VADL score continued to increase ${ }^{8}$. This finding shows that the DHI scale does not provide a variety range of intensity, as high values are reached in patients that still do most of the VADL activities by themselves or are minimally affected. It is important to highlight that such results hold for the different dimensions evaluated by those scales. For rehabilitation, the VADL brings more information to the clinician about what to work on with the patient, but the DHI can help to understand some emotional problems and situations that trigger symptoms. So, their results can complement each other in a comprehensive assessment.

Most of the time subjective perception evaluated by questionnaires is poorly correlated with objective assessment ${ }^{1}$. This study showed a moderate correlation between the VADL total score and the DGI. Patients can underestimate or overstate their own competence when describing $\mathrm{it}^{30}$. Another option for therapists that complements the self-assessment and the objective test is covert observation, i.e. watching the patients when they are unaware of being observed ${ }^{30}$. Therefore, comparing the results of all those measures can provide good information to the therapist about everyday life and help in treatment planning.

The patients also differ from healthy subjects in another study, in which the authors found no relationship between the vestibular disorder diagnoses and performance of the activities ${ }^{8}$. Thus, having a vestibular disorder is more important for the level of functional limitation than its etiology8. Although knowing the etiology can help clinicians to choose the best treatment available, the best option for benign paroxysmal positional vertigo (BPPV) is repositioning maneuvers and for unilateral vestibular hypofunction it is habituation exercises. In both cases, the level of function will help the clinician know the consequences of such diseases in the patient's everyday life and, with this information, plan the treatment. Therefore, symptoms of vertigo and imbalance, rather than the origin, should probably be the indication for using self-perceived scales ${ }^{31}$.

Elderly women with vestibular disorders had higher VADL total scores than men. This finding differs from the original study ${ }^{8}$, in which no difference was found between genders. In another activity scale, the VAP, women had higher perceived disability than the men ${ }^{6}$. This finding could be explained by the relationship between some activities and gender, such as performing household chores.

The results after VR confirm the responsiveness of the scale. Being exposed to the exercises provided by VR not only diminishes symptoms but can also improve self-confidence. This influence can be reflected in the way people perform daily activities. Further randomized clinical trials are needed to determine a cut-off score that will provide relevant predictive evidence of significant improvement after VR.

The exploratory factor analysis of the VADLBrazil showed 6 factors instead of the 3 subscales previously proposed by theory. The factor "Basic Mobility" derives its items from the Functional subscale plus the item "walking on a level surface". It represents mobility components of basic activities of daily living (ADL). ADL are the most basic activities involved in everyday independent function ${ }^{32}$, and walking is one of them. The items in the factor "Dressing the lower body" could be easily included in "Basic Mobility" if this were not a specific scale for evaluating patients with vestibular disorder. These activities require special movements, such as bending over or looking down, which often cause dizziness. The factor "Instrumental Mobility" comprises mobility components of instrumental activities of daily living (IADL), which describe activities necessary for adaptation to the environment and emphasize community activities ${ }^{32}$. Most of the items came from the previous Ambulation subscale, in which the activities are performed outside the home. The factor "Stairs" could also be added to the "Instrumental Mobility", but as it is a difficult task for such patients, and most of them need or prefer to use the handrail for more stability, those items are better interpreted together than with other components of mobility. The items in the factor "Households" are commonly in IADL scales, but as the response is gender-related the items had a better 
analysis together than being integrated with another factor. The most difficult or least performed items composed the factor "Multidimensional Activities". The tasks in this factor involve attention, mobility, and other sensorial resources.

One limitation of this study is the fact that most of our sample had associated diseases and took a lot of medication. Therefore, we cannot state that all the results of the VADL-Brazil can be attributed only to the vestibular disorder. Additionally, as a subjective scale, patient perception is also influenced by personality, anxiety, associated symptoms, and evolution of the disease ${ }^{1}$.

This study provided more data about the psychometric properties and usefulness of the VADL using the Brazilian version. As the population ages, the detailed evidence available about changes in ADL performance caused by vestibular disorders will be useful in public health and in treatment planning for older individuals. The use of a reliable and valid instrument in research and clinical practice increases the knowledge about vestibular disorders and allows the comparison of data from different care settings and populations, thus providing resources to improve patient care.

\section{References}

1. Duracinsky M, Mosnier I, Bouccara D, Sterkers O, Chassany O. Working Group of the Société Française d'Oto-Rhino-Laryngologie (ORL). Literature review of questionnaires assessing vertigo and dizziness, and their impact on patients' quality of life. Value Health. 2007;10:273-84. PMid:17645682. http://dx.doi. org/10.1111/j.1524-4733.2007.00182.x

2. Castro ASO, Gazzola JM, Natour J, Ganança FF. Versão brasileira do Dizziness Handicap Inventory. Pró-Fono Rev Atual Cient. 2007;19:97-104. http://dx.doi.org/10.1590/ S0104-56872007000100011

3. Cohen HS, Kimball KT. Development of the vestibular disorders activities of daily living scale. Arch Otolaryngol Head Neck Surg. 2000;126:881-7. PMid:10889001. http:// dx.doi.org/10.1001/archotol.126.7.881

4. Yardley L, Putman J. Quantitative analysis contributing to handicap and distress in vertigos patients: a questionnaire study. Clin Otolaryngol. 1992;17:231-6. http://dx.doi. org/10.1111/j.1365-2273.1992.tb01833.x

5. Marques AP, Mendes YC, Taddei U, Pereira CAB, Assumpção A. Brazilian-Portuguese translation and cross cultural adaptation of the activities-specific balance confidence (ABC) scale. Braz J Phys Ther. 2013;17(2):170-8. PMid:23778771.

6. Alghwiri AA, Whitney SL, Baker CE, Sparto PJ, Marchetti GF, Rogers JC, et al. The development and validation of the Vestibular Activities and Participation measure. Arch Phys Med Rehabil. 2012;93:1822-31. PMid:22465405. http://dx.doi.org/10.1016/j.apmr.2012.03.017

7. Alghwiri AA, Marchetti GF, Whitney SL. Content comparison of self-report measures used in vestibular rehabilitation based on the international classification of functioning, disability and health. Phys Ther. 2011;91:34657. PMid:21252307. http://dx.doi.org/10.2522/ ptj.20100255

8. Cohen HS, Kimball KT, Adams AS. Application of the vestibular disorders activities of daily living scale. Laryngoscope. 2000;110:1204-9. PMid:10892697. http:// dx.doi.org/10.1097/00005537-200007000-00026

9. Cohen HS, Sangi-Haghpeykar H. Canalith repositioning variations for benign paroxysmal positional vertigo. Otolaryngol Head Neck Surg. 2010;143:405-12. PMid:20723779 PMCid:PMC2925299. http://dx.doi. org/10.1016/j.otohns.2010.05.022

10. Salvinelli F, Trivelli M, Casale M, Firrisi L, Di Peco V, D'Ascanio L, et al. Treatment of benign positional vertigo in the elderly: a randomized trial. Laryngoscope. 2004;114:827-31. PMid:15126738. http://dx.doi. org/10.1097/00005537-200405000-00007

11. Cohen HS, Kimball KT. Increased independence and decreased vertigo after vestibular rehabilitation. Otolaryngol Head Neck Surg. 2003;128:60-70. PMid:12574761. http://dx.doi.org/10.1067/mhn.2003.23

12. Cohen HS, Kimball KT. Changes in a repetitive head movement task after vestibular rehabilitation. Clin Rehabil. 2004;18:125-31. http://dx.doi. org/10.1191/0269215504cr707oa

13. Resende CR, Taguchi CK, Almeida JG, Fujita RR. Reabilitação vestibular em pacientes idosos portadores de vertigem posicional paroxística benigna. Rev Bras Otorrinolaringol. 2003;69:535-540. http://dx.doi. org/10.1590/S0034-72992003000400015

14. Del Greco L, Walop W, McCarthy RH. Questionnaire development: Validity and reliability. CMAJ. 1987;136:699-700. PMid:3828925 PMCid:PMC1491926.

15. Aratani MC, Ricci NA, Caovilla HH, Ganança FF. Brazilian version of the Vestibular Disorders Activities of Daily Living Scale (VADL). Braz J Otorhinolaryngol. 2013;79(2):203-11. PMid:23670327. http://dx.doi. org/10.5935/1808-8694.20130036

16. Cohen HS, Kimball KT. Decreased ataxia and improved balance after vestibular rehabilitation. Otolaryngol Head Neck Surg. 2004;130:418-25. PMid:15100637. http:// dx.doi.org/10.1016/j.otohns.2003.12.020

17. Bertolucci PH, Brucki SM, Campacci SR, Juliano Y. The Mini-Mental State Examination in a general population: impact of educational status. Arq Neuropsiquiatr. 1994;52:1-7. PMid:8002795. http://dx.doi.org/10.1590/ S0004-282X1994000100001

18. Ricci NA, Aratani MC, Caovilla HH, Ganança FF. Effects of conventional versus multimodal vestibular rehabilitation 
on functional capacity and balance control in older people with chronic dizziness from vestibular disorders: design of a randomized clinical trial. Trials. 2012;13:246-253. PMid:23276084 PMCid:PMC3551791. http://dx.doi. org/10.1186/1745-6215-13-246

19. De Castro SM, Perracini MR, Ganança FF. Dynamic Gait Index-Brazilian version. Braz J Otorhinolaryngol. 2006;72:817-25. PMid:17308836.

20. Whitney SL, Wrisley DM, Brown KE, Furman JM. Is perception of handicap related to functional performance in persons with vestibular dysfunction? Otol Neurotol. 2004;25:139-43. PMid:15021773. http://dx.doi. org/10.1097/00129492-200403000-00010

21. Cawthorne T. The physiological basis for head exercises. J Chart Soc Physiother. 1944;29:106-7.

22. Cooksey FS. Rehabilitation in vestibular injuries. Proc R Soc Med. 1946;39:273-278. PMid:19993269 PMCid:PMC2181739.

23. Whitney SL, Wrisley DM, Marchetti G, Furman JM. The effect of age on vestibular rehabilitation outcomes. Laryngoscope. 2002;112:1785-90. PMid:12368616. http:// dx.doi.org/10.1097/00005537-200210000-00015

24. Vieira S. Introdução à Bioestatística. $4^{\mathrm{a}}$ ed. Rio de Janeiro: Elsevier; 2008.

25. Hosmer DW, Lemeshow S. Applied Logistic Regression. $2^{\text {a }}$ ed. New York: Wiley; 2000. PMid:10886529. http:// dx.doi.org/10.1002/0471722146

26. Pallant J. SPSS Survival Manual: A Step by Step Guide to Data Analysis Using SPSS. 4th ed. England: McGrawHill; 2010.
27. Hair JF, Anderson RE, Tatham RL, Black WC. Análise multivariada de dados. $5^{\text {a }}$ ed. Porto Alegre: Bookman; 2005.

28. Cronbach LJ. Fundamentos da testagem Psicológica. $5^{\text {a }}$ ed. Porto Alegre: Artes Medicas; 1996.

29. Aratani MC, Perracini MR, Caovilla HH, Gazzola JM, Ganança MM, Ganança FF. Disability rank in vestibular older adults. Geriatr Gerontol Int. 2011;11:50-4. PMid:20609000. http://dx.doi. org/10.1111/j.1447-0594.2010.00633.x

30. Cohen HS. Assessment of functional outcomes in patients with vestibular disorders after rehabilitation. NeuroRehabilitation. 2011;29:173-8. PMid:22027079.

31. Tamber AL, Wilhelmsen KT, Strand LI. Measurement properties of the Dizziness Handicap Inventory by cross-sectional and longitudinal designs. Health Qual Life Outcomes. 2009;7:101. PMid:20025754 PMCid:PMC2804706. http://dx.doi. org/10.1186/1477-7525-7-101

32. Roehrig BK, Hoeffken L, Pientka L, Wedding U. How many and which items of activities of daily living (ADL) and instrumental activities of daily living (IADL) are necessary for screening. Crit Rev Oncol Hematol. 2007;62(2):164-71. PMid:17169569. http://dx.doi. org/10.1016/j.critrevonc.2006.10.001

\section{Correspondence}

Natalia Aquaroni Ricci

Rua Afonso Celso 982, ap.12, Vila Mariana, CEP 04119-060, São Paulo, SP, Brazil e-mail: natalia_ricci@hotmail.com 